\title{
Impact of Built-up-Litter and Commercial Antimicrobials on Salmonella and Campylobacter Contamination of Broiler Carcasses Processed at a Pilot Mobile Poultry- Processing Unit
}

\author{
KaWang Li ${ }^{\dagger}$, Lacey Lemonakis ${ }^{\dagger}$, Brian Glover ${ }^{\dagger}$, Joseph Moritz and Cangliang Shen* \\ Davis College, Division of Animal and Nutritional Sciences, West Virginia University, Morgantown, WV, United States
}

The small-scale mobile poultry-processing unit (MPPU) produced raw poultry products are of particular food safety concern due to exemption of USDA poultry products inspection act. Limited studies reported the microbial quality and safety of MPPU-processed poultry carcasses. This study evaluated the Salmonella and Campylobacter prevalence in broiler ceca and on MPPU-processed carcasses and efficacy of commercial antimicrobials against Campylobacter jejuni on broilers. In study I, straight-run Hubbard $\times$ Cobb broilers (147) were reared for 38 days on clean-shavings (CS, 75) or built-up-litter (BUL, 72) and processed at an MPPU. Aerobic plate counts (APCs), coliforms, Escherichia coli, and yeast/molds (Y/M) of carcasses were analyzed on petrifilms. Ceca and carcass samples underwent microbial analyses for Salmonella and Campylobacter spp. using the modified USDA method and confirmed by API-20e test (Salmonella), latex agglutination immunoassay (Campylobacter), and Gram staining (Campylobacter). Quantitative polymerase chain reaction (CadF gene) identified the prevalence of C. jejuni and Campylobacter coli in ceca and on carcasses. In study II, fresh chilled broiler carcasses were spot inoculated with $C$. jejuni $\left(4.5 \log _{10} \mathrm{CFU} / \mathrm{mL}\right)$ and then undipped, or dipped into peroxyacetic acid (PAA) (1,000 ppm), lactic acid (5\%), lactic and citric acid blend (2.5\%), sodium hypochlorite (69 ppm), or a $\mathrm{H}_{2} \mathrm{O}_{2}-\mathrm{PAA}$ mix (SaniDate ${ }^{\circledR} 5.0,0.25 \%$ ) for $30 \mathrm{~s}$. Surviving $C$. jejuni was recovered onto Brucella agar. APCs, coliforms, and E. coli populations were similar $(P>0.05)$ on CS and BUL carcasses. Carcasses of broilers raised on BUL contained a greater $(P<0.05) \mathrm{Y} / \mathrm{M}$ population $\left(2.2 \log _{10} \mathrm{CFU} / \mathrm{mL}\right)$ than those reared on CS $\left(1.8 \log _{10} \mathrm{CFU} / \mathrm{mL}\right)$. Salmonella was not detected in any ceca samples, whereas $2.8 \%$ of the carcasses from BUL were present with Salmonella. Prevalence of Campylobacter spp., $C$. jejuni was lower $(P<0.05)$, and $C$. coli was similar $(P>0.05)$ in CS-treated ceca than BUL samples. Prevalence of Campylobacter spp., C. jejuni, and C. coli was not different $(P>0.05)$ on CS- and BUL-treated carcasses. All antimicrobials reduced $C$. jejuni by 1.2-2.0 log CFU/mL on carcasses compared with controls. Hence, raising broilers on CS and applying post-chilling antimicrobial treatment can reduce Salmonella and Campylobacter on MPPU-processed broiler carcasses.

Keywords: broiler carcasses, mobile poultry-processing unit, litter, antimicrobials, Salmonella, Campylobacter 


\section{INTRODUCTION}

Since July 2011, new performance standards have been established by the United States Department of Agriculture-Food Safety and Inspection Service (USDA-FSIS) in response to national baseline studies that required routine testing for Salmonella and Campylobacter in all processing plants. These new performance standards state that the percentage of Salmonella-positive samples must be $<7.5 \%$ and Campylobacter-positive samples should be $<10.4 \%$ (1). With the implementation of more rigorous standards for pathogen reduction by the USDA-FSIS, it is necessary for poultry processors to employ new or additional pre- and post-harvest interventions for effective control of Salmonella and Campylobacter throughout chicken processing.

Demand for locally grown products has increased due to consumer interest in sustainable agriculture and an expectation of improved flavor and nutrition. Interest in pastured poultry production and on-farm mobile slaughter of poultry has increased dramatically in the last 20 years. In the previous 5-10 years, some Mid-Atlanta states (Kentucky, Pennsylvania, Ohio, and Massachusetts) have offered mobile poultry-processing units (MPPUs) to small-scale farmers to facilitate production and processing of $\leq 1,000$ broilers per year for local and intrastate, direct sale to consumers under the inspection exemption by the USDA-FSIS Poultry Products Inspection Act. According to the West Virginia Department of Agriculture (WVDA), no smallscale poultry-processing facilities (including MPPUs) exist at West Virginia (WV). The lack of small-scale poultry-slaughtering facilities limits small-scale poultry producers in WV to local/ intrastate selling of $\leq 1,000$ birds per year. Small-scale farmers who wish to slaughter and sell poultry products locally must have them slaughtered and processed in an out-of-state USDAFSIS-inspected facility (2). To continue to grow small-scale local poultry industries at $\mathrm{WV}$, the WVDA is planning to assist smallscale poultry processors to install MPPUs at state-wide areas (Personal communication with Mr. Jerry Ours, Poultry Program Coordinator of WVDA). Therefore, it is important to conduct research projects from pre-harvest to post-harvest process to identify food safety risks associated with locally produced broilers, to provide supporting documentation for implementation of an MPPU, to secure local production and distribution of safe poultry meat in $\mathrm{WV}$, and eventually to decrease/eliminate health disparities through optimized local food systems in WV and the mid-Atlantic region.

From the pre-harvest prospective, locally small-scale poultry growers often reuse litter to rear consecutive broiler flocks. Litter is often reused for 1-2 years before full cleanout and replacing with new litter (3). Therefore, food safety concerns are raising about the reusing of litter especially for the challenge of control Campylobacter during poultry raising. There is limited research on the comparison of broilers reared on clean-shavings (SC) vs. built-up-litter (BUL) regarding the microbial quality and safety of broilers, including the colonization and contamination of Salmonella and Campylobacter spp. on broiler carcasses. The literature shows that the welfare, health, performance, and carcass quality of poultry are affected directly by litter quality (4). The samples utilized for the present study were collected from a small-scale broiler trial that compared the performance of industry-standard broilers reared on CS or BUL.

From the post-harvest processing prospect, the slaughter and carcass processing in MPPUs are carried out on a more manual basis instead of using industry-scale, large, automated commercial processing lines. Their products differ based on the variety of available equipment, producer resources, and facilities. This diversity, along with the absence of regulatory guidance, has failed to yield the data needed to validate the safety of raw chicken/ broiler carcasses and chicken parts produced by MPPUs. The limited application of antimicrobial intervention plus a final ice water-chilling process without application of post-chilling decontamination treatments makes locally grown MPPU-processed poultry products more vulnerable to infection by Salmonella and Campylobacter. Lactic acid (LA), peroxyacetic acid (PAA), sodium hypochlorite ( $\mathrm{SH}$ ), and a blend of lactic and citric acid (LCA) have been approved by USDA-FSIS to control food-borne pathogens during industry-scale poultry processing (5). The data available currently on industry-scale poultry processing have reported the efficacy of various commercial antimicrobials to control Salmonella and Campylobacter in the processing of poultry meat $(6,7)$. However, few studies have validated the efficacy of commercial antimicrobial interventions on MPPU-produced broiler meat.

Therefore, the present study had two main objectives. First, we wished to ascertain the populations of aerobic plate counts (APCs), total coliforms (TCCs), generic Escherichia coli, yeast, and molds on raw broiler carcasses and evaluate the prevalence of Salmonella and Campylobacter spp. in the ceca and on the carcasses of broilers processed at a university pilot-scale MPPU. Second, we wished to evaluate the efficacy of commercial antimicrobial agents against Campylobacter jejuni on MPPU-processed broiler carcasses.

\section{MATERIALS AND METHODS}

\section{Raising Broilers}

Broilers sampled for the present study were obtained from a study conducted at the West Virginia University (WVU) Poultry Farm, as reported previously by Glover et al. (8). Broilers were cared for according to guidelines set by the Animal Care and Use Committee of WVU. Briefly, 736 1-day-old straight-run Hubbard $\times$ Cobb chickens were obtained from a local hatchery and raised for 38 days with 174 chickens using in this study. Broilers had access to food and water ad libitum. Broilers were fed with a high-by product protein diet containing a $30 \%$ inclusion of wheat (high in non-starch polysaccharides). The diet formulated did not contain any antibiotics or coccidiostats. Litter was bagged and stored at the end of each replicate (three consecutive identical replicates were conducted) to allow each room to be disinfected appropriately between each replicate. Once rooms had been disinfected, litter and CS were redistributed. Two rooms within the WVU Poultry Farm Research Facility were utilized to completely remove litter and broilers to eliminate cross-contamination. One room was termed "CS" (Figure 1), and the second room was called "BUL" (Figure 1). There were 16 pens in CS or BUL 


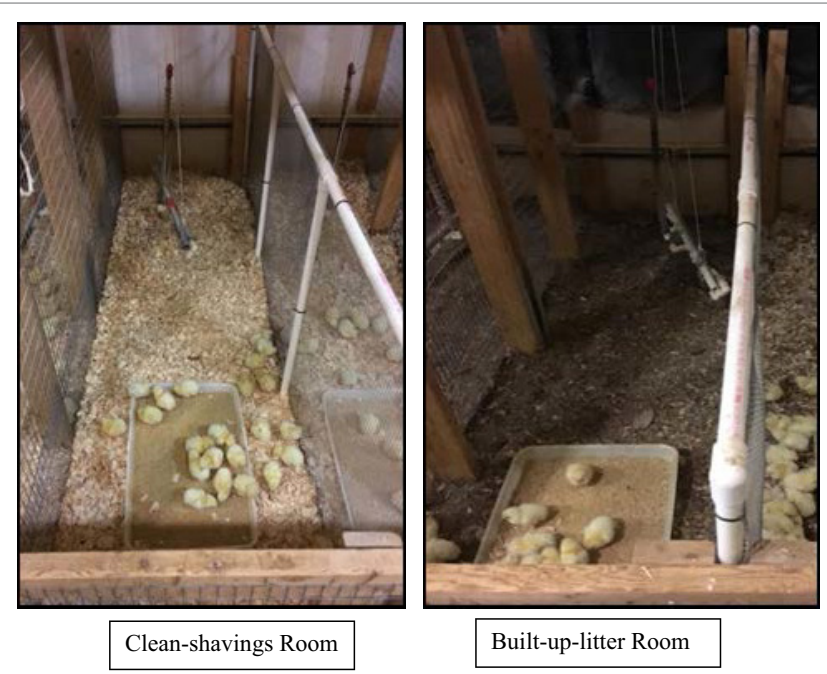

FIGURE 1 | Broilers were reared in "clean-shavings" and "built-up-litter" room.

room with 23 birds per pen, and a stocking density was 0.06 $\mathrm{m}^{2} /$ bird. At the end of each replicate, three to four broilers from eight pens from each room (CS or BUL) were collected and processed at the WVU pilot processing facility that mimicked an MPPU, which was replicated three times with a total of 174 broilers. For each replication, 25 broilers were from CS room, and 24 broilers were from BUL room. Litters from CS and BUL treatment were analyzed for Salmonella in a commercial microbial testing lab and no Salmonella ( $<1$ CFU/25 g litter) was detected in litters.

\section{Processing Broilers in an MPPU Facility}

The processing of aforementioned broilers was in an MPPU facility at WVU poultry farm with no application of antimicrobial agents. No Salmonella spp. was sampled from the MPPU facility according to the real-time polymerase chain reaction (PCR) test of the InvA gene (internal unpublished data). Broilers were killed with a hand knife and allowed for bleeding for $2 \mathrm{~min}$. After scalding and defeathering, the evisceration was conducted manually on a stainless-steel table with glove hands. Broiler carcasses were then rinsed in warm $\left(50^{\circ} \mathrm{C}\right)$ tap water before chilling in a static container with ice water for $24 \mathrm{~h}$. Ceca samples of each processed broilers were collected for later microbial analyses.

\section{Preparation of Broiler Carcasses and Ceca Samples}

After chilling for $24 \mathrm{~h}$, carcasses were added to a sterile chickensampling bag (Nasco, Fort Atkinson, WI, USA) rinsed with $400 \mathrm{~mL}$ of buffered peptone water (BPW; Hardy Diagnostics, Santa Maria, CA, USA) and followed by vigorous shaking for $60 \mathrm{~s}$ (9). Ceca samples were prepared by vertical cutting, addition into a sterile filtered Whirl-Pak@bag (Nasco) with 60 mL of BPW, followed by homogenization in a masticator (IUL Instruments, Barcelona, Spain) for $2 \mathrm{~min}$. The $60 \mathrm{~mL}$ of ceca solution was equally split into two tubes for further testing Salmonella and Campylobacter spp.

\section{Numeration of APCs, E. coli/TCCs, and Yeast/Molds (Y/M)}

The rinsate of each carcass sample was serially diluted 10 -fold into $0.1 \%$ BPW and plated onto APCs, E. coli/TCCs, and Y/M petrifilm (3M Microbiology, Saint Paul, MN, USA) for enumeration of the total population of aerobic bacteria, generic E. coli, TCCs, and $\mathrm{Y} / \mathrm{M}$, respectively, according to manufacturer instructions. Petrifilms were incubated at $25^{\circ} \mathrm{C}$ for $72 \mathrm{~h}$ (APCs), $35^{\circ} \mathrm{C}$ for $48 \mathrm{~h}$ (E. coli/TCCs), and $25^{\circ} \mathrm{C}$ for $120 \mathrm{~h}$ (Y/M) followed by manual counting of colonies.

\section{Isolation of Salmonella spp.}

The isolation of Salmonella spp. was used modified FDA-BAM methods (10) as described in the previous study of Li et al. (11). The aforementioned broiler BPW rinsate and $30 \mathrm{~mL}$ of ceca $\mathrm{BPW}$ solution were pre-enriched for $24 \mathrm{~h}$ at $35^{\circ} \mathrm{C}$. Then, $0.1 \mathrm{~mL}$ was transferred into a $10 \mathrm{~mL}$ of Rappaport-Vassiliadis broth for secondary enrichment $\left(24 \mathrm{~h}, 35^{\circ} \mathrm{C}\right)$. This was followed by streak plating onto XLT-4 agar and HardyCHROM ${ }^{\text {TM }}$ agar (Hardy Diagnostics) and incubation for $24 \mathrm{~h}$ at $35^{\circ} \mathrm{C}$. The one to two presumptive typical Salmonella colonies from XLT-4 agar and HardyCHROM agar were confirmed using a Salmonella Latex Agglutination Test kit (Oxoid, Basingstoke, UK) and API 20E Test kit (bioMẻrieux, Durham, NC, USA). Salmonella Typhimurium ATCC 14028 was used as a positive control from a biochemistry and immunology test.

\section{Isolation of Campylobacter spp.}

The isolation of Campylobacter spp. was according to the previous study of Scheinberg et al. (9). $30 \mathrm{~mL}$ of broiler-carcass rinsate or ceca sample solution was mixed with $30 \mathrm{~mL}$ of $2 \times$ Bolton's broth (Hardy Diagnostics). These mixtures were incubated for $48 \mathrm{~h}$ at $42^{\circ} \mathrm{C}$ under microaerophilic conditions $\left(5.0 \% \mathrm{O}_{2}, 10 \% \mathrm{CO}_{2}\right.$, and $85 \% \mathrm{~N}_{2}$ ) in a 2.5 -L microaerophilic jar (Oxoid). Following incubation, a loopful of Bolton's broth was streaked on modified Campy-Cefex Agar (Hardy Diagnostics) and incubated for $72 \mathrm{~h}$ at $42^{\circ} \mathrm{C}$ under the microaerophilic conditions described above. Presumptive colonies on the modified Campy-Cefex Agar gar were confirmed using the Campy-latex Agglutination Test (Oxoid), oxidase test (Hardy Diagnostics), and Gram staining to observe for "corkscrew" morphology.

\section{Identification of C. jejuni and Campylobacter coli}

The identified Campylobacter colonies were regrown into $10 \mathrm{~mL}$ of Bolton's broth for $48 \mathrm{~h}$ at $42^{\circ} \mathrm{C}$ under the microaerophilic conditions described above. Then, the growing solutions were used to test for the presence of C. jejuni and C. coli in ceca or carcass samples using a TaqMan ${ }^{\circledR}$ kit (Fisher Scientific, Fair Lawn, NY, USA) following the manufacturer instruction. Total DNA was extracted according to the method described in $\mathrm{Li}$ et al. (11) followed by the real-time PCR detection of CadF gene (12). Reactions were conducted in a total volume of $20 \mu \mathrm{L}$, which included $10 \mu \mathrm{L}$ of $2 \times$ qPCR MasterMix, $1 \mu \mathrm{L}$ of $C$. jejuni or $C$. coli primer/probe mix, $1 \mu \mathrm{L}$ of internal extraction control primer/probe mix, $3 \mu \mathrm{L}$ of RNAse/DNAse free water, and $5 \mu \mathrm{L}$ of 
extracted DNA. Amplification of the CadF gene was done on a 7300 real-time PCR system (Applied Biosystems, Foster City, CA, USA). Conditions for the amplification were $37^{\circ} \mathrm{C}$ for $15 \mathrm{~min}$, $95^{\circ} \mathrm{C}$ for $2 \mathrm{~min}$, and 30 cycles of $95^{\circ} \mathrm{C}$ for $10 \mathrm{~s}$ and $60^{\circ} \mathrm{C}$ for $1 \mathrm{~min}$.

\section{Preparation of $\boldsymbol{C}$. jejuni Inoculum}

Strains RM5032, RM1188, and RM1464 of C. jejuni (kindly supplied by Dr. Nereus Gunther from USDA-ARS, Wyndmoor, PA, USA) were used in this study. Each individual C. jejuni strain was maintained on Brucella agar (Hardy Diagnostics) at $4^{\circ} \mathrm{C}$ under microaerophilic conditions $\left(5.0 \% \mathrm{O}_{2}, 10 \% \mathrm{CO}_{2}\right.$, and $\left.85 \% \mathrm{~N}_{2}\right)$ in a 2.5-L microaerophilic jar (Oxoid). The colonies grown on Brucella agar were verified by a Campy-latex Agglutination Test kit. To prepare the inoculum, single colonies of each C. jejuni strain were inoculated individually into $10 \mathrm{~mL}$ of Bolton's broth and incubated for $48 \mathrm{~h}$ at $42^{\circ} \mathrm{C}$ under the microaerophilic environment described above. Before experimentation, the three cultures of C. jejuni were combined, harvested by centrifugation $(5,000 \times g$, $15 \mathrm{~min}$, room temperature), duplicate washed with $0.1 \% \mathrm{BPW}$ to remove residual media, centrifuged, and resuspended in $0.1 \%$ BPW. The bacterial population of the final inoculum suspension was $7 \log$ colony-forming units (CFU)/mL.

\section{Inoculation of C. jejuni on Broiler Carcasses}

The MPPU-processed carcasses from WVU poultry farms were transferred to a food microbiology laboratory at WVU and used in experiments within 24-48 h. Broiler carcasses were assigned randomly to a treatment group and inoculated with the threestrain mixture of $C$. jejuni. This was achieved by addition of five drops of $200 \mu \mathrm{L}$ of the bacterial mixture on medial and lateral sides (13) and placement on foil paper in a biohazard hood for $20 \mathrm{~min}$ to allow bacterial attachment. The final inoculation level of the organism on carcasses was $4.54 \pm 1.24 \log \mathrm{CFU} / \mathrm{mL}$ of carcass rinsate.

\section{Antimicrobial Treatment of Broiler Carcasses}

The C. jejuni-inoculated broiler carcasses were left untreated (control) or immersed in antimicrobial solutions: PAA $(0.1 \%$; $\mathrm{pH}, 3.0 ; 15.7^{\circ} \mathrm{C}$; Birko, Henderson, CO, USA), LA (5\%; pH, 2.0; $15.3^{\circ} \mathrm{C}$; Birko), LCA $\left(2.5 \%\right.$; Chicxide $\left.^{\circledR}\right)$, SH (freely available chlorine, 67-69 ppm; $\mathrm{pH}, 9.1 ; 14.4^{\circ} \mathrm{C}$; Birko), and a PAA/hydrogen peroxide mix (SaniDate ${ }^{\circledR}$ 5.0, 0.25\%; pH, 7.25; $15.2^{\circ} \mathrm{C}$; Arbico Organics, Tucson, AZ, USA). Treatment involved immersing three carcasses into a $10-\mathrm{L}$ prepared antimicrobial solution with manual agitation $(\approx 500 \mathrm{rpm})$ for $30 \mathrm{~s}$ with draining for $2 \mathrm{~min}$. The tested concentration of PAA, LA, and LCA was in the range allowed in USDA-FSIS Directive 7120.7 (5). PAA concentration was determined using a Titration Drop Test kit (LaMotte Co., Chestertown, MD, USA) (14). The concentration of LA, LCA, and SaniDate 5.0 was calculated according to factsheet supplied by the manufacturer. The initial and residual free-chlorine concentration was measured using the $N, N$ diethyl-1,4 phenylenediamine sulfate method (15). For SH solution, after 30-s treatment of broiler carcasses, the initial free-chlorine concentration was
67-69 ppm, and the residual free-chlorine concentration was $11.8 \mathrm{ppm}$. Therefore, the mean initial and final residual freechlorine concentration was $\approx 40$ ppm (i.e., $<50$ ppm and in accordance with USDA-FSIS Directive 7120.7) (5). The $\mathrm{pH}$ and temperature of antimicrobial solutions were measured using a digital pH meter (Fisher Scientific).

\section{Microbiological Analyses}

Numeration of C. jejuni on broiler carcasses was done according to the methods described by Nagel et al. (14) and Gunther et al. (16). Carcasses were placed in a sterile chicken-sampling bag (Nasco) and rinsed with $200 \mathrm{~mL}$ of BPW supplemented with $0.1 \%$ sodium thiosulfate (Fisher Scientific) followed by vigorous shaking for $60 \mathrm{~s}$ (14). After 10-fold serial dilution in Bolton's broth, the dilution liquid was spread plated onto Brucella agar (16) and incubated for $48 \mathrm{~h}$ at $42^{\circ} \mathrm{C}$ in the microaerophilic jar $(5.0 \%$ $\mathrm{O}_{2}, 10 \% \mathrm{CO}_{2}$, and $85 \% \mathrm{~N}_{2}$ ) before manual counting of colonies. The growth of Campylobacter colonies on Brucella agar was also confirmed using the Campy-latex Agglutination test.

\section{Data Analyses}

In study I, three replications were conducted for the experiment. For each replication, treatments of CS (25 broilers) and BUL (24 broilers) were organized in a split-plot design consisting of a $2 \times 2$ factorial arrangement in a randomized block design for broilers reared at the WVU Poultry Farm. In study II, the antimicrobial intervention test was repeated twice with three carcasses per treatment per repeat (a total of six samples of carcasses per treatment). A chi-square test (significance level at 0.05 ) from $\mathrm{JMP}^{\circledR}$ was done to compare differences in the percentage of Salmonella, Campylobacter spp., C. jejuni, and C. coli on broiler carcasses between treatment of CS and BUL. Data on microbial quality (converted to $\log \mathrm{CFU} / \mathrm{mL}$ ) of broiler carcasses (APCs, $E$. coli, TCCs, and Y/M) were analyzed using Student's $t$-test by SAS v9.2 (SAS Institute, Cary, NC, USA). One-way ANOVA of SAS v9.2 was used to analyze the survival population and reduction of $C$. jejuni on broiler carcasses after antimicrobial treatment. To compare the level of reduction of the C. jejuni response to various antimicrobial agents, reduction data were determined using the following equation:

$$
\text { Reduction ratio }=\log _{10}\left(N_{0} / N\right)
$$

where $N_{0}$ is the mean control plate counts and $N$ is the plate count of each individual antimicrobial-treated sample. Mean values were compared with a significance level of $\alpha=0.05$ as determined by Tukey's honest significant difference test.

\section{RESULTS}

\section{Microbial Quality of Broiler Carcasses}

As indicators of microbial hygiene, the population of APCs, TCCs, E. coli, and Y/M of broiler carcasses from CS and BUL groups is quantified in Table 1. There was no significant difference $(P>0.05)$ in APCs, TCCs, and $E$. coli between carcasses in the CS room and BUL room (Table 1). The mean value (in $\log \mathrm{CFU} / \mathrm{mL}$ ) of APCs was 3.4-3.5, TCCs was 2.2-2.5, and 
TABLE 1 | Mean \pm SD of microbial populations (log CFU/mL of sample rinsate) measured as aerobic plate counts (APCs), total coliforms (TCCs), Escherichia coli, and yeast/molds (Y/M) on broiler carcasses in "clean-shavings (CS)" and "built-up-litter (BUL)" rooms.

\begin{tabular}{lcccc}
\hline Treatment & APCs & TCCs & E. coli & Y/M \\
\hline CS $(n=75)$ & $3.4 \pm 0.2^{\mathrm{a}}$ & $2.5 \pm 0.3^{\mathrm{a}}$ & $2.1 \pm 0.6^{\mathrm{a}}$ & $1.8 \pm 0.3^{\mathrm{a}}$ \\
$\mathrm{BUL}(n=72)$ & $3.5 \pm 0.2^{\mathrm{a}}$ & $2.2 \pm 0.4^{\mathrm{a}}$ & $2.1 \pm 0.5^{\mathrm{a}}$ & $2.2 \pm 0.4^{\mathrm{b}}$
\end{tabular}

Mean values with different lowercase letters within a column are significantly different $(P<0.05)$.

E. coli was 2.1 of all carcasses (Table 1 ). The total population of Y/M on CS broiler carcasses was lower by $0.4 \log \mathrm{CFU} / \mathrm{mL}$ $(P<0.05)$ than BUL carcasses (Table 1$)$.

\section{Prevalence of Salmonella spp. in Broiler Ceca and on Carcasses}

The presence of Salmonella spp. on broiler carcasses was tested and confirmed by the Salmonella Latex Agglutination Test and API 20E strips with a biochemical profile code 6704752 (17). There was no contradiction in results between these two tests. Overall, a Salmonella spp. was not detected on any ceca samples tested regardless of CS and BUL treatments, suggesting that Salmonella spp. was not colonized in all broilers tested. Salmonella spp. was not detected on CS-treated carcasses, and it was present on $2.8 \%$ ( 2 of 72 samples) of carcasses in the BUL room (Table 2 ).

\section{Prevalence of Campylobacter spp. in Broiler Ceca and on Carcasses}

Overall, the prevalence of Campylobacter spp. in broiler ceca $(64.6-84.6 \%)$ and on carcasses (50-56.2\%) was shown in Table 3. In general, the prevalence of Campylobacter spp. in the ceca in the CS room were lower $(P<0.05)$ than those in the BUL room (Table 3$)$ but similar $(P>0.05)$ on the carcasses of broilers compared to the samples in BUL room (Table 3 ). Among the broilers in the CS room, Campylobacter spp. was colonized in $64.6 \%$ (49 of 75) of ceca samples, and was present on $50 \%$ (37 of 75) of carcasses (Table 3). Among BUL-treated samples, $84.6 \%$ (61 of 72) of ceca samples were colonized with, and $56.3 \%$ (41 of 72) of carcasses were carrying Campylobacter spp. (Table 3).

Quantitative PCR revealed that the prevalence of $C$. jejuni was lower $(P<0.05)$ in the ceca $(14.7$ vs. $30.6 \%)$ but similar on carcasses (19.4 vs. $28.6 \%$ ) of CS broilers compared to the BUL samples (Table 3). C. coli was present at a similar level $(P>0.05)$ in the ceca $(36.0$ vs. $30.6 \%)$ and $(P>0.05)$ on the carcasses $(19.4$ vs. $25.7 \%$ ) of CS and BUL-treated samples (Table 3).

\section{Antimicrobial Efficacy in Inactivation of C. jejuni}

The survival and reduction values of $C$. jejuni on post-chilled broiler carcasses treated with $0.1 \%$ PAA, 5.0\% LA, 2.5\% LCA, $69 \mathrm{ppm} \mathrm{SH}$, or $0.25 \%$ SaniDate 5.0 are shown in Table 4 . The initial level of C. jejuni recovered on inoculated broiler carcasses was $4.54 \log \mathrm{CFU} / \mathrm{mL}$. All tested antimicrobial treatments
TABLE 2 | Prevalence of Salmonella spp. in the ceca and on the carcasses of broilers in "clean-shavings (CS)" and "built-up-litter (BUL)" rooms and processed in a mobile poultry-processing unit.

\begin{tabular}{lcr}
\hline Treatment & Ceca & Carcasses \\
\hline CS & $0 \%(0 / 75)^{\mathrm{a}}$ & $0 \%(0 / 75)^{\mathrm{a}}$ \\
BUL & $0 \%(0 / 72)^{\mathrm{a}}$ & $2.8 \%(2 / 72)^{\mathrm{a}}$
\end{tabular}

Mean values with the same lowercase letters within a column are not significantly different $(P>0.05)$.

TABLE 3 | Prevalence of Campylobacter spp., Campylobacter jejuni, and Campylobacter coli in the ceca and on the carcasses of broilers in "cleanshavings (CS)" and "built-up-litter (BUL)" room and processed in a mobile poultry-processing unit.

\begin{tabular}{lccccccc}
\hline \multirow{2}{*}{ Treatment } & \multicolumn{3}{c}{ Ceca } & & \multicolumn{3}{c}{ Carcass } \\
\cline { 2 - 4 } \cline { 7 - 8 } & C. spp. & C. jejuni & C. coli & & C. spp. & C. jejuni & C. coli \\
\hline CS & $64.6 \%$ & $14.7 \%$ & $36 \%$ & $50 \%$ & $19.4 \%$ & $19.4 \%$ \\
& $(49 / 75)^{\mathrm{a}}$ & $(11 / 75)^{\mathrm{a}}$ & $(27 / 75)^{\mathrm{a}}$ & $(37 / 75)^{\mathrm{a}}$ & $(14 / 75)^{\mathrm{a}}$ & $(14 / 75)^{\mathrm{a}}$ \\
\multirow{2}{*}{ BUL } & $84.6 \%$ & $30.6 \%$ & $30.6 \%$ & $56.3 \%$ & $28.6 \%$ & $25.7 \%$ \\
& $(61 / 72)^{\mathrm{b}}$ & $(22 / 72)^{\mathrm{b}}$ & $(22 / 72)^{\mathrm{a}}$ & $(41 / 72)^{\mathrm{a}}$ & $(21 / 72)^{\mathrm{a}}$ & $(18 / 72)^{\mathrm{a}}$ \\
\hline
\end{tabular}

Mean values with different lowercase letters within a column are significantly different $(P<0.05)$.

TABLE 4 | Survival and reduction (mean $\pm \mathrm{SD}$ ) of $C$. jejuni (counts on Brucella agar) recovered from inoculated broiler carcasses left untreated or treated with peroxyacetic acid (PAA, $\left.0.1 \%, \mathrm{pH} 3.0,15.7^{\circ} \mathrm{C}\right)$, lactic acid ( $L A, 5 \%, \mathrm{pH}$ $\left.2.0,15.3^{\circ} \mathrm{C}\right)$, lactic and citric acid (LCA) blend (2.5\%, $\left.\mathrm{pH} 2.7,15.2^{\circ} \mathrm{C}\right)$, sodium hypochlorite $\left(\mathrm{SH}, 67-69 \mathrm{ppm}, \mathrm{pH} 9.1,14.4^{\circ} \mathrm{C}\right)$, a PAA and hydrogen peroxide mixer (SaniDate ${ }^{\circledR}$ 5.0, 0.25\%, $\mathrm{pH} 7.2,15.2^{\circ} \mathrm{C}$ ) for $30 \mathrm{~s}$.

\begin{tabular}{lcc}
\hline Treatment & Survival $(\log \mathbf{C F U} / \mathbf{m L})$ & Reduction $(\log \mathbf{C F U} / \mathbf{m L})$ \\
\hline Control & $4.54 \pm 1.24^{\mathrm{a}}$ & - \\
PAA & $2.49 \pm 0.77^{\mathrm{b}}$ & $2.04 \pm 0.77^{\mathrm{a}}$ \\
LA & $3.11 \pm 0.70^{\mathrm{b}}$ & $1.43 \pm 0.70^{\mathrm{ab}}$ \\
LCA & $3.11 \pm 0.17^{\mathrm{b}}$ & $1.43 \pm 0.71^{\mathrm{ab}}$ \\
SH & $2.89 \pm 0.15^{\mathrm{b}}$ & $1.65 \pm 0.15^{\mathrm{ab}}$ \\
SaniDate $^{\circledR} 5.0$ & $3.28 \pm 0.51^{\mathrm{b}}$ & $1.26 \pm 0.51^{\mathrm{b}}$ \\
\hline
\end{tabular}

"-" indicates reduction data are not available.

Mean values with different lowercase letters within a column are significantly different $(P<0.05)$.

reduced the $C$. jejuni on broiler carcasses significantly $(P<0.05)$ compared with the untreated control. Specifically, $0.1 \%$ PAA reduced $C$. jejuni by $2.04 \log \mathrm{CFU} / \mathrm{mL}$ compared with the control, which was better $(P<0.05)$ than all the other antimicrobials (Table 4). In the present study, dipping carcasses in $5.0 \% \mathrm{LA}$ reduced the $C$. jejuni population by $1.43 \mathrm{log} \mathrm{CFU} /$ $\mathrm{mL}$ compared with the untreated control $(P<0.05)$ (Table 4$)$. Broiler carcasses dipped into SH (69 ppm), 2.5\% LCA, and $0.25 \%$ SaniDate 5.0 reduced the C. jejuni population by 1.65 , 1.43 , and $1.26 \log \mathrm{CFU} / \mathrm{mL}$, respectively, and there were no significant difference $(P>0.05)$ between these treatments (Table 4).

\section{DISCUSSION}

Aerobic plate counts are used to assess the total microbial population on broiler carcasses. The coliform population 
(especially the generic E. coli population) indicates the potential fecal contamination on processed meat and poultry products according to USDA-FSIS (9). The population of $\mathrm{Y} / \mathrm{M}$ of processed broiler carcasses has not been reported widely. The value for APCs was similar to, but that for TCCs and E. coli was higher than the value noted by Scheinberg et al. (9). They reported that the value (in $\log \mathrm{CFU} / \mathrm{mL}$ ) for APCs, TCCs, and $E$. coli was approximately 4.0, 1.5, and 0.9 , respectively, in whole chickens at farmers' markets in Pennsylvania (9). Northcutt et al. (18) found a similar value (in $\log \mathrm{CFU} / \mathrm{mL}$ ) for APCs (3.2) and E. coli (1.7) on post-chilled conventional chicken rinsates to our results. Although the yeast and molds population recovered from broiler carcasses of CS treatment is significantly lower than the BUL treatment, a 0.4-log difference is generally not considered biologically significant (19). Overall, the levels of APCs, TCCs, E. coli, and Y/M found on MPPU-processed broiler carcasses in the present study suggest that small-scale growers of broilers who use MPPUs should implement antimicrobial interventions during processing or apply post-chilling interventions to reduce the background microflora on broiler surfaces.

A high level of Salmonella spp. on chickens processed at locally commercialized poultry facility has been reported in other studies $(9,20)$. For example, Trimble et al. (20) reported that $43 \%$ of chicken carcasses processed in an USDA-inspected facility were Salmonella-positive. Also Scheinberg et al. (9) found 20-28\% of Salmonella-positive broiler carcass samples from farmers' markets and local supermarkets in Pennsylvania. The Salmonella present on those small, locally processed broiler carcasses may be attributed to variances in farm management and lack of regulatory guidance. In the present study, very low percentage of Salmonella spp. was identified in broiler ceca and on carcasses regardless of CS and BUL treatment, which is in agreement with the studies of Killinger et al. (21) and Trimble et al. (20). They reported that Salmonella was not detected on carcasses processed in the university pilot-scale MPPU in the states of Washington (21) and Arkansas (20). These results might be explained by the following four reasons. First, applying good cleaning and sanitization practices could reduce Salmonella spp. effectively on broilers (22). The WVU poultry-raising room and pilot MPPU facility was cleaned repeatedly with hot water along with physically sweeping and applying commercial detergent and chlorinated water afterward. Second, compared to the commercial poultry-processing facility, the university pilot-scale MPPU was less frequently used, therefore less cross-contamination would occur. Third, due to budgetary restraints only a limited sample size $(23.9 \%, 174$ of 736$)$ of ceca and broiler samples were tested for Salmonella spp. Therefore, the results may not accurately reflect the Salmonella profile of the entire raised broilers. Finally, in this study, Salmonella and Campylobacter both occupy the same gastrointestinal tract of broilers; therefore, it is possible that Campylobacter was present in significant amounts and Salmonella was not detected.

Campylobacter spp., especially C. jejuni and C. coli, are the two major Campylobacter species and commonly cause human gastroenteritis if undercooked poultry meat is eaten (12). The percentage of Campylobacter spp. on MPPU-processed broilers has not been studied widely. Overall, the prevalence of
Campylobacter spp. in broiler ceca and on carcasses was much higher than the percentage of Salmonella. Findings are in accordance with the study of Trimble et al. (20), which suggest that for small-scale broiler producers, the management practices used to control Salmonella effectively might have only a slight effect on Campylobacter due to the difference in the physiology and ecology of these two pathogens in production and processing environments $(20,23)$. The high percentage of Campylobacter spp. observed in the present study may have been due to (1) use of a single-stage static scalder; (2) the practice of manual evisceration; (3) a single, static chilling tub without any antimicrobial agents (which may have resulted cross-contamination of broiler carcasses during the pilot-scale MPPU process).

Ceca is the main source of Campylobacter colonization in broilers. The impact of CS and BUL on the colonization of Campylobacter spp., C. coli, and C. jejuni in ceca of broilers were investigated in this study. CS reduced the percentage of Campylobacter spp. and C. jejuni but did not affect the percentage of $C$. coli compared to the BUL treatment. This mixed result might be explained by the two reasons. On one side, BUL was bagged, stored, and maintained the same litter throughout each trial, whereas CS was replaced if "caking" occurred. This process may have allowed for increased colonization of Campylobacter spp. and C. jejuni in BUL-treated cecum. On the other side, the colonization of $C$. coli might be caused by the complex factors of the broiler cecum, rather than attributed to the practices of litter including using old "dirty" litter repeatedly (24). No significant difference of Campylobacter spp., C. jejuni, and $C$. coli detected on broiler carcasses regardless of they were reared on BUL or CS treatment indicate that simply application of litter treatment including replacing old dirty litter with CS in the raising room did not directly influence the levels of Campylobacter on broiler carcasses. A further antimicrobial intervention is necessary during the post-harvest broiler processing to control Campylobacter level in the final broiler carcasses.

Results of this study showed that Campylobacter was dominant on MPPU-processed broiler carcasses; therefore, validation of the efficacy of various commercial antimicrobial agents against this pathogen after chilling was important. Nagel et al. (14) and Chen et al. (25) also reported that PAA $(0.04-0.1 \%)$ is the most effective antimicrobial agent used during post-chilling dipping to decontaminate Campylobacter on poultry products compared with chlorine, cetylpyridinium chloride, and lysozyme. Nagel et al. (14) reported that $0.1 \%$ PAA achieved a reduction of $2.03 \log \mathrm{CFU} / \mathrm{mL}$ of C. jejuni on broiler carcasses processed in an industry-scale pilot post-chilling dipping tank. Chen et al. (25) found that $0.1 \%$ PAA reduced Campylobacter by $\approx 1.5 \mathrm{log} \mathrm{CFU} / \mathrm{g}$ in ground chicken meat. PAA is a combination of peracetic acid and hydrogen peroxide, and it denatures proteins and disrupts bacterial cell walls (26). PAA at $<2,000 \mathrm{ppm}(0.2 \%)$ has been approved by USDA-FSIS for application on poultry carcasses since $2001(6,7)$, and it is the most prevalent antimicrobial agent used in the poultry industry (7). Small-scale poultry producers in Pennsylvania and the WV area who currently own or will purchase MPPUs wish to know the antimicrobial efficacy of PAA due to the concerns 
of "organic" processing. The present study provides important, validated data for them.

Lactic acid at $<5.0 \%$ is approved by the USDA-FSIS as an antimicrobial agent applied on broiler carcasses before or after chilling (5). In the present study, dipping carcasses in 5.0\% LA reduced the C. jejuni population by $1.43 \log \mathrm{CFU} / \mathrm{mL}$ compared with the untreated control $(P<0.05)$ (Table 4). Coşansu and Ayhan $(27)$ dipped the legs and breasts of chickens into 1 and 3\% LA and achieved reductions of $0.36-1.36$ and $1.27-1.98 \log \mathrm{MPN} / \mathrm{cm}^{2}$, respectively. Burfoot et al. (28) sprayed 4 and $8 \%$ LA onto chicken carcasses and reduced the Campylobacter on skin surfaces by 0.4-0.8 and $1.9 \log \mathrm{CFU} / \mathrm{g}$, respectively. Potential undesirable sensory and quality concerns have been raised upon application of LA on broiler carcasses (29).

In the present study, broiler carcasses dipped into $\mathrm{SH}$ (69 ppm), 2.5\% LCA and $0.25 \%$ SaniDate 5.0 reduced the C. jejuni population by $1.65,1.43$, and $1.26 \log \mathrm{CFU} / \mathrm{mL}$, respectively, and there were no significant difference $(P>0.05)$ between these treatments (Table 4). Recently, SH (commonly referred to as "free chlorine") has lost its dominant position as an antimicrobial agent used in poultry-meat processing due to: the requirement of a high concentration; rapid reaction with organic matter; a poultry-meat trade issue between the USA and Russia $(7,14,25)$. There is a growing interest in the development and evaluation of other chemical antimicrobials as chlorine alternatives. LCA (Chicxide; a buffered blend of LA and citric acid) at $\leq 2.5 \%$ is approved for use on poultry-meat surfaces (5), and its antimicrobial efficacy against Salmonella spp. has been evaluated on broiler carcasses (30). SaniDate 5.0 contains $23 \%$ hydrogen peroxide and 5.3\% PAA and has been shown to control food-borne pathogens on food-contact surfaces effectively. It is also recommended by the WV Small Farm Center for use on poultry meat for small-scale poultry growers in WV (personal communication with Dr. Tom McConnell, Program Leader of the WV Small Farm Center). Results of the present study suggest a similar reduction effect on Campylobacter by LCA and SaniDate 5.0 compared with SH. Hence, LCA and SaniDate 5.0 could be used by local, small-scale MPPU poultry processors during post-chilling.

In conclusion, results of this study suggest that the development of good clean and sanitizing practices may control Salmonella on broiler carcasses effectively. Broilers reared on CS could be beneficial for the pre-harvest control of Campylobacter compared with broilers reared on BUL. Results of the present study confirmed that application of post-chilling antimicrobialdipping treatments (especially PAA) could be a potential intervention approach to control Campylobacter on locally processed broilers using an MPPU. These results could contribute to the development of the new USDA-FSIS 5-year strategic plan for control of Salmonella in poultry-meat products (31). Our data could also assist WV state and local regulatory agencies to assess the potential risk and develop control strategies for Salmonella and Campylobacter in the application of MPPU processes for local poultry growers.

\section{ETHICS STATEMENT}

Broilers sampled for the present study were obtained from a study conducted at the WVU Poultry Farm, as reported previously by Glover et al. (8). Broilers were cared for according to guidelines set by the Animal Care and Use Committee of WVU. Briefly, 736 1-day-old straight-run Hubbard $\times$ Cobb chickens were obtained from a local hatchery and raised for 38 days with 174 chickens using in this study. Broilers had access to food and water ad libitum. Broilers were fed with a high-by product protein diet containing a 30\% inclusion of wheat (high in non-starch polysaccharides). The diet formulated did not contain any antibiotics or coccidiostats. Litter was bagged and stored at the end of each replicate (three consecutive identical replicates were conducted) to allow each room to be disinfected appropriately between each replicate. Once rooms had been disinfected, litter and CS were redistributed. Two rooms within the WVU Poultry Farm Research Facility were utilized to completely remove litter and broilers to eliminate crosscontamination. One room was termed "CS" (Figure 1) and the second room was called "BUL" (Figure 1). There were 16 pens in CS or BUL room with 23 birds per pen, and a stocking density was $0.06 \mathrm{~m}^{2} /$ bird. At the end of each replicate, three to four broilers from eight pens from each room (CS or BUL) were collected and processed at the WVU pilot processing facility that mimicked an MPPU, which was replicated three times with a total of 174 broilers. For each replication, 25 broilers were from CS room, and 24 broilers were from BUL room. Litters from CS and BUL treatment were analyzed for Salmonella in a commercial microbial testing lab, and no Salmonella ( $<1 \mathrm{CFU} / 25 \mathrm{~g}$ litter) was detected in litters.

\section{AUTHOR CONTRIBUTIONS}

KL conducted poultry processing, microbial pathogen testing, reference organization, and drafted manuscript. LL conducted antimicrobial validation study and data collection and analysis. BG raise all broiler carcasses and revised the manuscript. JM managed the poultry farm and coordinated the project. CS generated the idea of this project and drafted, revised, and finalized the manuscript.

\section{FUNDING}

This research was supported in part by the United States Department of Agriculture, National Institute of Food and Agriculture (NIFA) Hatch Program (grant number WVA00684), NIFA-Non-Land Grant Colleges of Agriculture (NLGCA) Capacity Building Program (2015-70001-23486), and West Virginia University Faculty Senate Grant (R16027).

\section{SUPPLEMENTARY MATERIAL}

The Supplementary Material for this article can be found online at http://journal.frontiersin.org/article/10.3389/fvets.2017.00088/ full\#supplementary-material. 


\section{REFERENCES}

1. Unites States Department of Agriculture-Food Safety and Inspection Service (USDA-FSIS). New Performance Standards for Salmonella and Campylobacter in Young Chicken and Turkey Slaughter Establishments; New Compliance Guides. Washington, DC: Federal Register (2010). p. 27288-94.

2. Peters C, Hansen E, Clingerman J, Hereford A, Askins N. West Virginia Food System Opportunities and Constraints in Local Food Supply Chains. (2012). Available from: https://downstreamstrategies.com/documents/reports_publication/DS_wv_food_system_opportuities_and_constraints_in_local_food_ supply_chains.pdf.

3. Payne JB, Li X, Santos FBO, Sheldon BW. Characterization of Salmonella from three commercial North Carolina broiler farms. Int J Poult Sci (2006) 5:1102-9. doi:10.3923/ijps.2006.1102.1109

4. Torok VA, Hughes RJ, Ophel-Keller K, Ali M, MacAlpine R. Influence of different litter materials on cecal microbiota colonization in broiler chickens. Poult Sci (2009) 88:2474-81. doi:10.3382/ps.2008-00381

5. Unites States Department of Agriculture-Food Safety and Inspection Service (USDA-FSIS). Safe and Suitable Ingredients Used in the Production of Meat, Poultry, andEggProducts. FSISDirective7120.1, Revision39.(2017). Availablefrom:www. fsis.usda.gov/wps/wcm/connect/bab10e09-aefa-483b-8be8-809a1f051d4c/ 7120.1.pdf?MOD=AJPERES

6. Oyarzabal OA. Reduction of Campylobacter spp. by commercial antimicrobials applied during the processing of broiler chickens: a review from the United States perspective. J Food Prot (2005) 68:1752-60. doi:10.4315/0362-028X-68.8.1752

7. McKee S. Salmonella and Campylobacter Control during Poultry Processing. Atlanta, Georgia: International Poultry Scientific Forum (2011).

8. Glover BG, Foltz KL, Ryan KJ, Moritz JS. Effects of feed form, environment, and caloric density on energy partitioning and subsequent broiler performance. Poult Sci (2016) 95(E-Suppl 1):17.

9. Scheinberg J, Doores S, Cutter C. A microbiological comparison of poultry products obtained from farmers' markets and supermarkets in Pennsylvania. J Food Saf (2013) 33:259-64. doi:10.1111/jfs.12047

10. United States Food and Drug Administration (US-FDA). Chapter 5: Salmonella. Bacteriological Analytical Manual Online (2014). Available from: http://www.fda.gov/Food/FoodScienceResearch/LaboratoryMethods/ ucm070149.htm.

11. Li KW, Weidhaas J, Lemonakis L, Khouryieh H, Stone M, Jones L, et al. Microbiological quality and safety of fresh produce in West Virginia and Kentucky farmers' markets and validation of a post-harvest washing practice with antimicrobials to inactivate Salmonella and Listeria monocytogenes. Food Control (2017) 79:101-8. doi:10.1016/j.foodcont.2017.03.031

12. Konkel ME, Gray SA, Kim BJ, Garvis SG, Yoon J. Identification of the enteropathogens Campylobacter jejuni and Campylobacter coli based on the cadF virulence gene and its product. J Clin Microbiol (1999) 37:510-7.

13. Scott BR, Yang X, Geornaras I, Delmore RJ, Woerner DR, Reagan JO, et al. Antimicrobial efficacy of a sulfuric acid and sodium sulfate blend, peroxyacetic acid, and cetylpyridinium chloride against Salmonella on inoculated chicken wings. J Food Prot (2015) 78:1967-72. doi:10.4315/0362-028X.JFP-15-170

14. Nagel GM, Bauermeister LJ, Bratcher CL, Singh M, McKee SR. Salmonella and Campylobacter reduction and quality characteristics of poultry carcasses treated with various antimicrobials in a post-chill immersion tank. Int J Food Microbiol (2013) 165:281-6. doi:10.1016/j.ijfoodmicro.2013.05.016

15. Shen C, Luo Y, Nou X, Wang Q, Millner P. Dynamic effects of free chlorine concentration, organic load, and exposure time on the inactivation of Salmonella, Escherichia coli O157:H7 and non-O157 Shiga toxin-producing E. coli. J Food Prot (2013) 76:386-93. doi:10.4315/0362-028X.JFP-12-320

16. Gunther NW 4th, Sites J, Sommers C. The effects of high-pressure treatments on Campylobacter jejuni in ground poultry products containing polyphosphate additives. Poultry Sci (2015) 94:2297-302. doi:10.3382/ps/pev199

17. Levy D, Beck N, Kossik A, Patti T, Meschke J, Calicchia M, et al. Microbial safety and quality of fresh herbs from Los Angeles, Orange County and Seattle farmers' markets. J Sci Food Agric (2014) 95:2641-5. doi:10.1002/jsfa.6996
18. Northcutt JK, Cason JA, Smith DP, Buhr RJ, Fletchert DL. Broiler carcass bacterial counts after immersion chilling using either a low or high volume of water. Poult Sci (2006) 85:1802-6. doi:10.1093/ps/85.10.1802

19. National Advisory Committee on Microbiological Criteria for Foods. Parameters for determining inoculated pack/challenge study protocols. J Food Prot (2010) 73:140-202. doi:10.4315/0362-028X-73.1.140

20. Trimble LM, Alali WQ, Gibson KE, Ricke SC, Crandall P, Jaroni D, et al. Salmonella and Campylobacter prevalence and concentration on pastureraised broilers processed on-farm, in a mobile processing unit, and at small USDA-inspected facilities. Food Control (2013) 34:177-82. doi:10.1016/j. foodcont.2013.04.024

21. Killinger KM, Kannan A, Bary AI, Cogger CG. Validation of a 2 percent lactic acid antimicrobial rinse for mobile poultry slaughter operations. J Food Prot (2010) 73:2079-83. doi:10.4315/0362-028X-73.11.2079

22. Ingmer H. Challenges of Campylobacter jejuni in poultry production. Int J Food Microbiol (2011) 145:S110. doi:10.1016/j.ijfoodmicro.2010.12.015

23. Newell DG, Fearnley C. Sources of Campylobacter colonization in chickens. Appl Environ Microbiol (2003) 69:4343-51. doi:10.1128/AEM.69.8.4343-4351.2003

24. Chinivasagam HN, Estella W, Rodrigues H, Mayer DG, Weyand C, Tran T, et al. On-farm Campylobacter and Escherichia coli in commercial broiler chickens: re-used bedding does not influence Campylobacter emergence and levels across sequential farming cycles. Poult Sci (2016) 95:1105-15. doi:10.3382/ps/pew003

25. Chen X, Bauermeister LJ, Hill GN, Singh M, Bilgili SF, McKee SR. Efficacy of various antimicrobials on reduction of Salmonella and Campylobacter and quality attributes of ground chicken obtained from poultry parts treated in a postchill decontamination tank. J Food Prot (2014) 77:1882-8. doi:10.4315/0362-028X.JFP-14-114

26. Adler J, Cain-Helfrich E, Shen C. Reductions in natural microbial flora, generic Escherichia coli and pathogenic Salmonella on jalapeno peppers processed in a commercial antimicrobial cabinet - a pilot plant trial. J Food Prot (2016) 79:1854-9. doi:10.4315/0362-028X.JFP-16-222

27. Coşansu S, Ayhan K. Effects of lactic and acetic acid treatments on Campylobacter jejuni inoculated onto chicken leg and breast meat during storage at $4^{\circ} \mathrm{C}$ and $-18^{\circ} \mathrm{C}$. J Food Process Preserv (2010) 34:98-113. doi:10.1111/j.1745-4549.2008.00320.x

28. Burfoot D, Allen V, Mulvey E, Jewell K, Harrison D, Morris V. Reducing Campylobacter numbers on chicken carcasses using lactic acid in processing plants. Int J Food Sci Technol (2015) 50:2451-7. doi:10.1111/ijfs.12912

29. Mani-López E, García HS, López-Malo A. Organic acids as antimicrobials to control Salmonella in meat and poultry products. Food Res Intern (2012) 45:713-21. doi:10.1016/j.foodres.2011.04.043

30. Laury AM, Alvarado MV, Nace G, Alvarado CZ, Brooks JC, Echeverry A, et al. Validation of a lactic acid- and citric acid-based antimicrobial product for the reduction of Escherichia coli O157:H7 and Salmonella on beef tips and whole chicken carcasses. J Food Prot (2009) 72:2208-11. doi:10.4315/ 0362-028X-72.10.2208

31. Unites States Department of Agriculture-Food Safety and Inspection Service (USDA-FSIS). Strategic Plan: Strategic Performance Working Group Salmonella Action Plan (2013). Available from: https://www.fsis.usda.gov/wps/wcm/connect/aae911af-f918-4fe1-bc42-7b957b2e942a/sap-120413.pdf?mod=ajperes

Conflict of Interest Statement: The authors declare that the research was conducted in the absence of any commercial or financial relationships that could be construed as a potential conflict of interest.

Copyright $\odot 2017$ Li, Lemonakis, Glover, Moritz and Shen. This is an open-access article distributed under the terms of the Creative Commons Attribution License (CC BY). The use, distribution or reproduction in other forums is permitted, provided the original author(s) or licensor are credited and that the original publication in this journal is cited, in accordance with accepted academic practice. No use, distribution or reproduction is permitted which does not comply with these terms. 